\title{
Economic consequences of resource trade-offs for special disaster-blessed industries: the case of COVID-19 pandemic Economic consequences of COVID-19 pandemic
}

\author{
Muhammad Jawad Sajid ${ }^{1}$ \\ ${ }^{1}$ School of Management, Xuzhou University of Technology, Xuzhou, China.
}

\begin{abstract}
COVID-19 pandemic has spread to almost every nation in the world. Most of the available literature on the economic effects of COVID-19 focuses mainly on the recessionary effects of COVID-19 on different industries and aggregate economies. However, some industries, such as masks (surgical and N95, etc.), ventilators and miscellaneous medical services, benefit economically from the current COVID-19 disaster. More and more resources have been diverted to these industries due to the increased demand of these special industries. Excessive demand from these special industries will eventually return to normal or, under special conditions, fall below their normal (usual) demand once the pandemic has ended. Which, in turn, will not only affect these special industries, but can also have an impact on the recovery of aggregate economies around the globe. The study presents a comprehensive model for the different phases of the short-term lifecycle of these special industries. Presentation of the working and economic backlash resulting from the eventual decline in demand of these industries may encourage world economic policymakers to look beyond the current disastrous situation and to devise the necessary monetary and fiscal policies for the future COVID19 free era. Otherwise, it will be difficult for the economies recovering from COVID-19 pandemic to move back to normal functioning, because the additional resources (such as labor and capital) allocated to these special industries may be idle for some time, which may increase the burden and drag the recovering economies of the COVID-19 pandemic into a deeper recession even when the pandemic is over.
\end{abstract}

\section{Introduction}

The new corona virus that causes the disease known as COVID-19 has been declared a pandemic by the WHO (World Health Organization) as it has reached almost every nation [1]. According to data from Johns Hopkins University, COVID-19 caused approximately 151,000 deaths, more than 2,200,000 people were infected, and approximately 540,000 patients were recovered [1]. Besides the health concerns, the current COVID-19 has a significant impact on the global economy, the experts have predicted that COVID-19 will decrease the global GDP growth by 0.5 per cent for the year of 2020 i.e. from 2.9 per cent to 2.4 per cent [2]. Governments will not be able to minimize both the mortality and economic consequences of the COVID-19 pandemic, keeping deaths to the lowest possible level will be a top priority for the public, so governments should devise measures to protect economies from a certain recession [3]. The world's largest economies and economic blocs have committed billions of dollars' worth of monetary and fiscal stimulus to save their economies from the negative recessionary impact of the COVID-19 pandemic [4]. While most industries are facing depression due to reduced demand, some industries are benefiting from the ongoing COVID-
19 pandemic due to a massive surge in demand for their products and services.

Disaster blessed industries (DBI's) are defined in this study as: industries that are already operating in the economy, producing products or services at a certain price and quantity, are transformed into short-term DBI's due to actual or hypothetical threats that dramatically increase their prices and quantities above normal levels. Although the causes of most of these threats especially those from the natural disasters like earthquakes, floods and pandemics etc. are external to the realm of economics, and hence mostly not considered; therefore, we can only explain their economic effects [5]. For instance, natural disasters like earthquakes or floods will cause a drastic increase in the demand quantity of rescue services, dry food, and the construction industry (to repair or reconstruct the damaged infrastructure (roads, bridges, railroads, airports etc.) and other buildings (houses, offices, hospitals, shopping malls etc.). Similarly, the current COVID-19 pandemic has led to massive increase in the demand of the different type of masks (surgical and N95 masks etc.), ventilators and health services (e.g. medical staff, medicines, hospital beds and hospitals) etc. The masks, ventilators and health services industry already existed before the virus and were producing a specified quantity at some specified price to fulfill their final 
demand i.e. both the (demand and supply) quantity and prices were sticking at some normal level in the short run. But the global spread of the new corona virus has resulted in an increase in both demand and supply, while prices are increasing all the time. This shows that, in this case, the usual economy of demand and supply price equilibrium is not working. Because the producer is no longer the pricetaker and the consumer is willing to buy more of the product, even if the price increase from the current level, i.e. the price increase, may not result in a decrease in demand. The additional value (quantities multiplied by prices) produced by the mask, ventilator or medical industry above its usual value (quantities multiplied by prices) will present the value of the short-term DBI industry (see Appendix section for the numerical estimation of the additional value of the DBI's created due to some unexpected disaster like COVID-19). This additional value is not expected to have existed in normal circumstances.

Normally, increased demand will not result in capital investment, but, if fear persists for longer periods of time, industries may be inclined or forced to make capital investments as well. As the industries are already working so this disaster (pandemic) will normally not result in the creation of new industries. At the same time the creation of this short term DBI will naturally result in decreased demand for some other industries due to a number of interconnected phenomenon's. On the consumption side the budget constraint (tradeoff) between alternatives, uncertainty leading to saving rather than consumption and investment, and finally the decrease in the income of the consumers because of the fact that job market, businesses and other institutions usually do not operate fully, under uncertain conditions like the case of COVID-19 forced lockdown in various countries etc. [6] will drive the demand for other industries decrease significantly in the short-run. On the other hand, the supply side for other industries will firstly be affected by the economy's tradeoff between increasing the production of the DBIs (whose demand has surged due to life threating situation) versus increasing the production of other industries (whose demand has already declined) the answer is obvious that the economy will try to increase the supply of the shortrun DBIs by utilization of its scarce resource rather than the contrary. Secondly, the lockdown, fear, and the increase in labor health problems (i.e. labor affected with COVID-19) etc. will also reduce the availability of production factors (especially labor) further effecting the supply (production) of other industries. Now because of the scarcity of resources for the short term DBI's (like the shortage of masks, ventilators, medical staff and even hospitals etc. under the COVID-19 pandemic [7], [8] the supply (production) rather than the demand (consumption) will take the main role. In normal circumstances demand plays the main role but in case of scarcity of resources supply becomes the main concern [9]-[11]. The short or medium run fear event (like COVID-19) will most likely slow down the economic activity and even move the economies in to recession. Many major world governments are turning to Keynesian economics to save them from the recessionary impacts of the COVID-19. The challenge will not be over once the corona pandemic fades away. Hypothetically, the short-run DBIs will once again begin to work to their normal capacity. The capacity of the short-run DBIs to move back to their normal working position depends on the timeframe for which the DBIs were created, the longer the timeframe the more difficult and complex it will be for the short-run DBIs to move back towards their normal functioning. Because the longer time duration will force the sort-run DBIs to hire additional workers and even to invest in fixed capital assets. Once demand has returned to normal levels, additional labor hired will be laid off, which may increase the rate of frictional and cyclical unemployment. The real problem will arise for those industries or sectors that have been forced to invest in fixed capital (assets). Because their additional fixed assets will be idle under normal circumstances, i.e. machinery, building and furniture etc. will be unused (unless they are sold at reasonable prices, which will also take a lot of effort and resources). In addition, there is also a possibility that demand for products (masks and ventilators, etc.) of the short-term DBIs may even fall below normal demand or even reach zero for a short or very short period of time, once the threat (i.e. COVID-19 pandemic) is over. This situation may arise where people have wrongly anticipated either the duration of the fear event or the quantity of short-term DBIs products needed to survive the fear event (such as the COVID-19 pandemic), which will lead to an excessive quantity purchased than is actually required and this excess quantity will be stored (at home or business) that can be used for some time after the fear event. The enormous costs of maintaining idle fixed assets and the lack of demand will result in large losses for these vital industries (masks, ventilators, even hospitals, etc.), which can eventually put these key industries out of business. This will result in all their workforce becoming unemployed and a huge increase in frictional, structural (because some unemployed workers may not have the skills needed in other industries) and cyclical unemployment. Such situations will force the already struggling economy (economies) to sink deeper into recession or depression. Making it more difficult for the short-term DBIs and the aggregate economies to move back to normal production. In this case, policymakers should support short-term DBIs through a variety of measures (fiscal and monetary) even after the threat of a short-term fear event (such as the current COVID-19) has decreased. Otherwise, it may be very difficult for these industries (especially those that made capital investments) to survive as soon as this (fear) forced increase in demand is reduced.

Most of the studies have ignored the economic effects of DBIs once the current COVID-19 is over. For example, [12] created seven different scenarios for the potential spread of COVID-19 and studied the short-term effects of these different scenarios on the global macroeconomic outcomes and financial markets. [13] used the "Keynesian supply shocks" theory to present the effects of reduced labor supply, industrial shutdowns and exits, which could lead to variations in aggregate demand that are even greater than supply shocks. [14] created different scenarios and presented the effects of COVID-19 on GDP in 30 countries under different scenarios. [15] presented 
the effect of COVID-19 on the liquidity of listed companies in 26 countries. [16] estimated the impact of COVID-19 on global financial markets. Some studies have also focused on the regional economic and financial impact of COVID-19. [17] presented three potential economic and financial responses from the United States to COVID-19. [18] estimated the economic impact on outside economies of the potential lockdown of Tokyo City due to COVID-19. [19] presented the economic impact of COVID-19 on the African region. [20] presented a cost-benefit analysis of social distancing in the United States.

First of all, this study clearly defines the theory behind the birth and the death of short-term DBIs. Secondly, there is no such theory or study which presents the life-cycle of short-term DBIs. It is important to understand the shortrun DBIs because most of the policymakers via different fiscal or monetary options only look at the possibilities of moving the economies out of recession during the phase of natural disasters like the current COVID-19 pandemic etc. However, once the short-run economies move back to their normal positions, there is a risk that the extra labor and long term investment made in the DBIs due to hyped demand during the period of specific short run fears will not be sustainable any more. And the labor can be laid off and the extra fixed resources (machinery etc.) will be idle i.e. became of no use. This can lead to these important industries like the masks or the ventilator industries suffer unstainable losses and can lead to their permanent shutdown. Which can force the recently recovered economy to move back to a much severe recession or depression than it actually faced in the period of the shortrun fear events like the current COVID-19 pandemic. Table 1 contains the list of regional COVID-19 "laboratory-confirmed" cases and related deaths.

Table1. Regions with "laboratory-confirmed" corona related deaths and cases

\begin{tabular}{|l|c|c|}
\hline \multicolumn{3}{|c|}{ Corona cases and deaths a } \\
\hline \multicolumn{1}{|c|}{ Country } & $\begin{array}{c}\text { Total } \\
\text { confirmed } \\
\text { cases }\end{array}$ & Total deaths \\
\hline Africa & 382,563 & 7,139 \\
\hline Americas & $5,915,551$ & 266,736 \\
\hline Eastern Mediterranean & $1,187,620$ & 28,102 \\
\hline Europe & $2,809,848$ & 200,651 \\
\hline South-East Asia & 974,389 & 25,619 \\
\hline Western Pacific & 229,590 & 7,499 \\
\hline Subtotal for all regions & $11,499,561$ & 535,746 \\
\hline Other & 741 & 13 \\
\hline Grand total & $\mathbf{1 1 , 5 0 0 , 3 0 2}$ & $\mathbf{5 3 5 , 7 5 9}$ \\
\hline
\end{tabular}

a. Based on World Health Organization [21].

\section{Results}

\subsection{The DBls economic modeling}

Figure 1, presents the supply model for the short term DBIs. The creation of short run DBI consists of three main phases (stages). Point $\mathrm{N}$ in figure 1 presents the normal price and quantity demanded of a particular. In the normal (very) short run market, the prices of a commodity are sticky, and the producers are willing to sell more units of a product at a given price. Once the fear event occurs, consumers will be demanding more at increased prices. Phase 1 is marked by the increase in both the prices and the quantity of a certain industry above its normal prices and quantity. This is due to unusual circumstance like COVID-19 pandemic, the consumer will be willing to buy more quantity (e.g. masks and ventilators) even if the price increases. Similarly, the producers will be happy to provide more and increase prices. Producers will increase their supplies by employing more short-term resources like, increasing labor hours, labor shifts, employing more daily wages or short contract labor etc. But after a certain level of production increase the industry will reach its maximum potential, and will not be able to produce more even with increase in demand prices. This point is marked as MSO presenting the point of maximum short run output with the current level of fixed capital (assets), this situation marks the phase 2 of the short-run DBI era. At this point the firm will start increasing its price, because consumer is in immense need of the product. But after a certain level of price increase, the consumer despite having an immense need will not be willing to buy. This point is presented as the MPD (maximum price paid by demand) in the figure 1 , and marks the beginning of phase 3 . Under phase 3 , if the firm wants to meet demand or increase revenue it has to make more capital investment. This will be a rare case where the time duration of the unexpected event is prolonged due to lack of proper planning or resources employed to deal with the situation, or specific inventions or innovations are not discovered for some years to come. For example, in case of new COVID-19 pandemic, if due to lack of proper plaining, due to the failure of proper research funding or due to the failure of the scientific community in finding a cure (vaccine and medicines etc.) for the COVID-19 disease, the pandemic is prolonged to several years. The entrepreneurs and governments will be faced with tough decisions of increasing the fixed capital investment in short run DBIs (masks, ventilators or hospital industry) to meet the critical demand. The practical example of the fixed investment in short-run DBIs is of two new hospitals built to specifically deal with the COVID-19 effected patients in Wuhan China. Where initially the existing hospitals were used to deal with the new corona virus patients by increasing staff working hours, and importing staff from other regions. But once the maximum capacity was reached the government decided to make fixed investment in building new COVID-19 specific hospitals. Now as the event is short or medium run after a certain time the additional need (demand) of the DBIs will diminish with the diminishing of the event, and the 
demand will move back to its original position $\mathrm{N}$, this point is marked as POR (point of return) in the figure 1 . Another possibility is that people have bought and stored more of a particular product during a period of short-term fear, such as the COVID-19 pandemic, which they actually needed to consume during the pandemic. In this case even when the fear is over, the demand might not go back to the normal level. This will force the suppliers to reduce both the quantity and prices imposed by the lack of demand. Any point below the normal demand at the red dotted line like the point $\mathrm{BN}$ (below normal) in figure 1 presents this scenario. It may be below the normal demand or it may also be zero for a period of time. The challenge for the governments is that even after the short run fear (like COVID-19 pandemic) fades away, and the economy seems to be going back to the normal state, they should be aware of the backlash effects of the creation of the short run DBIs, which can prolong the recession period or even result in economic collapse. Here, the governments through necessary short run subsides, tax rebates, cheap loans or even direct investment to these industries can save the economy from the backlashes caused by the birth of the short-run DBIs.

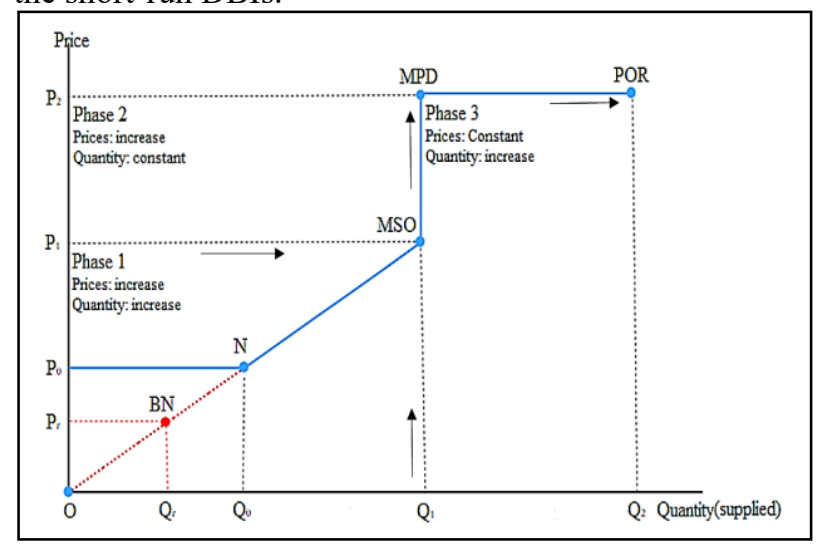

Fig1. Supply curve for a short run disaster blessed industry

(DBI).

\section{Conclusion and policy implications}

This study presented the theory behind the creation and the death of the short run DBIs. While it is almost impossible to eliminate the creation of short-term DBIs, their economic impact can be reduced by well-developed planning and preparations for (unpredictable) natural disasters such as floods, earthquakes and pandemics (such as COVID-19). Short-run DBIs are already functioning as normal industries within the economy and are created mainly due to the occurrence of some unexpected natural disasters such as the floods, earthquakes and pandemics (COVID-19) etc. Once the short run fear is over, these DBIs usually go back to their normal functioning which marks the death of the DBIs. However, their creation is not without economic shocks, i.e. the additional demand for short-run DBIs will see more and more resources allocated to these industries, which will result in less resources available to other industries due to the opportunity cost (the trade-off between the allocation of resources to different alternatives). During the period of short-term fear, normal economic activity tends to slow down, i.e. economies may go into recession. As is the case in the current era of the COVID-19 pandemic, many governments have turned to fiscal and monetary incentives to help boost the economy. But the problem will not fade away as soon as the short-term fear dies. Additional resources such as labor and fixed capital resources allocated to the short-run DBIs will no longer be required. The lay-off of additional labor may increase the rate of frictional, structural and finally cyclical unemployment in the economy. Fixed investment will be idle and, as a result, will increase the burden on the shortrun DBIs and the aggregate economy. And there is also the possibility of a lack of normal demand for short-term DBIs for some time when the event of fear fades away. These factors can not only push the recently recovered economies deeper into recession, but can also force the vital industries (such as masks and ventilators) to shut down businesses temporarily or permanently. Governments should keep this in mind and support shortterm DBIs through different monetary and fiscal incentives to reduce their expected losses and to help these industries continue to run their businesses.

\section{Appendix: methodology}

\subsection{Value of short run disaster blessed industry (DBI)}

The value of the short-run DBI is obtained by taking the difference between the value at the end or during the short-run fear event (like the COVID-19) and the normal value (the value of the industry just before the short-run fear event or if the value is not available the last known value close to the start of the fear event). The value here means that the quantity produced is multiplied by the unit price of the quantity produced. The method for the estimation of the value of the DBI during different phases (stages) is presented below.

$V D B I_{1}=\left(Q_{1} \times P_{1}\right)-\left(Q_{0} \times P_{0}\right)=V_{1}-V_{n}$

$V D B I_{2}=\left(Q_{1} \times P_{2}\right)-\left(Q_{1} \times P_{1}\right)=V_{2}-V_{1}$ $V B D I_{3}=\left(Q_{2} \times P_{2}\right)-\left(Q_{1} \times P_{2}\right)=V_{3}-V_{2}$

Where $V D B I_{1}, V D B I_{2}$ and $V D B I_{3}$ present the additional value produced by the short run BDI during different stages, $Q_{0}, Q_{1}$ and $Q_{2}$ present the quantities supplied by the target industry including its normal and additional quantity due to the existence of the fear event. $P_{0}, P_{1}$ and $P_{2}$ presents the corresponding prices for the quantity produced. $V_{1}, V_{2}$ and $V_{3}$ the total value produced by the DBI during different phases (stages), and $V_{n}$ presents it normal value. From the above equations we can easily drive the total additional value produced during the different stages of the short run life-cycle of the DBI.

$$
\begin{aligned}
& V D B I_{t}=\left(Q_{2} \times P_{2}\right)-\left(Q_{0} \times P_{0}\right)=V_{3}-V_{n} \\
= & V D B I_{1}+V D B I_{2}+V D B I_{3}
\end{aligned}
$$

Where $V D B I_{t}$ presents the total value of the short run DBI during different stages. The entering of the short run DBI in to different stages depends upon the time duration of the short run fear event. It means that the value of a short run DBI may or may not include all three stages. We can also easily estimate the value of the DBI at any random point in time through the following equation. 
$V D B I_{r}=\sum_{r=1}^{n}\left(Q_{r} \times P_{r}\right)-\left(Q_{0} \times P_{0}\right)=V_{r}-V_{n}$

(5)

Where $V D B I_{r}$ presents the value of the short run DBI at any random point (time). $Q_{r}$ and $P_{r}$ present the quantity and the price at any randomly selected point (time). $V_{r}$ presents the total value including the original (normal) value at the randomly selected point (time).

When the value of $V D B I_{t}$ becomes equal to the value of $V_{n}$ the DBI has moved back to the status of the normal industry, but if the value of $V D B I_{t}$ becomes less than the value of $V_{n}$, it will indicate that after the end of short-run fear period the industry has suffered less demand than it is expected during the normal circumstances and hence it is forced to supply lesser quantity at lesser prices than its normal supply quantity and prices. On the other hand, if the value of $V D B I_{t}$ is greater than $V_{n}$ it implies that we are still in the period of the short run fear.

$V D B I_{t}=V_{n}=$

The industry has returned back to its normal position

$V D B I_{t}<V_{n}=$

The supply quantity and prices are less than their normal position

$V D B I_{t}>V_{n}=$ The industry is working as short run $D B I$

\section{Acknowledgment}

The author would like to thank the anonymous reviewer for his/her valuable comments.

\section{References}

1. Aljazeera, "Timeline: How the new coronavirus spread," News / Corona virus Panademic, 18-Apr2020. [Online]. Available: https://www.aljazeera.com/news/2020/01/timelinechina-coronavirus-spread-200126061554884.html.

2. M. Gupta, A. Abdelmaksoud, M. Jafferany, T. Lotti, R. Sadoughifar, and M. Goldust, "COVID-19 and economy," Dermatol. Ther., no. March, p. 13329, 2020.

3. R. M. Anderson, H. Heesterbeek, D. Klinkenberg, and T. D. Hollingsworth, "How will country-based mitigation measures influence the course of the COVID-19 epidemic?," Lancet, vol. 395, no. 10228, pp. 931-934, 2020.

4. A. MacSwan, "Factbox: The economic remedies for the coronavirus," Thomson Reuters, 2020. [Online]. Available: https://www.reuters.com/article/us-healthcoronavirus-economy-policy-fac/factbox-theeconomic-remedies-for-the-coronavirusidUSKBN2121C4. [Accessed: 03-Apr-2020].

5. J. Schumpeter, Business Cycles. A Theoretical, Historical and Statistical Analysis of the Capitalist Process. New York, Toronto, London: McGraw-Hill Book Company, 1939.

6. J. Kaplan, L. Frias, and M. McFall-Johnsen, "A third of the global population is on coronavirus lockdown - here's our constantly updated list of countries and restrictions," Business Insider, 18-Apr-2020.

7. M. L. Ranney, V. Griffeth, and A. K. Jha, "Critical Supply Shortages — The Need for Ventilators and Personal Protective Equipment during the Covid-19 Pandemic,” N. Engl. J. Med., vol. Perspectiv, pp. 1-3, 2020.

8. Advisory Board, "Amid coronavirus, will hospitals run out of face masks? (Or ventilators? Or beds?)," 2020. [Online]. Available: https:/www.advisory.com/dailybriefing/2020/03/12/facemasks. [Accessed: 19-Apr2020].

9. J. Y. Park, "The supply-driven input-output model: A reinterpretation and extension," Cell, vol. 213, pp. 550-9979, 2007.

10. E. Davar, "Input-Output System Models: Leontief versus Ghosh," 15th Int. Input-Output Conf., pp. 117,2005

11. A. Ghosh, Experiments with Input-Output Models. London: Cambridge University Press, 1964.

12. W. McKibbin and R. Fernando, "The Global Macroeconomic Impacts of COVID-19: Seven Scenarios," Crawford, 19/2020, 2020.

13. V. Guerrieri, G. Lorenzoni, L. Straub, and I. Werning, "Macroeconomic Implications of COVID-19: Can Negative Supply Shocks Cause Demand Shortages?," Cambridge, 26918, 2020.

14. N. Fernandes, "Economic Effects of Coronavirus Outbreak (COVID-19) on the World Economy," 2020.

15. A. De Vito and J. Gómez, "Estimating the COVID-19 cash crunch : Global evidence and policy," J. Account. Public Policy, vol. 39, no. 2, p. 106741, 2020.

16. D. Zhang, M. Hu, and Q. Ji, "Financial markets under the global pandemic of COVID-19," Financ. Res. Lett., no. April, p. 101528, 2020.

17. H. Hafiz, S.-Y. Oei, D. M. Ring, and N. Shnitser, "Regulating in Pandemic : Evaluating Economic and Financial Policy Responses to the Coronavirus Crisis," Boston, 3/17/2020, 2020.

18. H. Inoue and Y. Todo, "The Propagation of the Economic Impact through Supply Chains: The Case of a Mega-City Lockdown against the Spread of COVID-19.," SSRN Electron. J., pp. 1-11, 2020.

19. J. E. Ataguba, "COVID-19 Pandemic, a War to be Won: Understanding its Economic Implications for Africa," Appl. Health Econ. Health Policy, vol. 18, no. 3, pp. 325-328, 2020.

20. L. Thunström, S. Newbold, D. Finnoff, M. Ashworth, and J. Shogren, "The Benefits and Costs of Using Social Distancing to Flatten the Curve for COVID-19,' J. Benefit-Cost Anal., pp. 1-17, 2020.

21. World Health Organization, "Coronavirus disease (COVID-2019) situation reports," 2020. 